\title{
Geotecnologias Aplicadas A Recursos Hídricos: Um Estudo de Caso da Bacia Hidrográfica do Córrego Arapuá - Três Lagoas/MS
}

Geotechnologies Applied To Water Resources: A Case Study Of The Hydrographic Basin Of The Arapuá Stream - Três Lagoas/MS

Geotecnologías Aplicadas A Los Recursos Hídricos: Un Estudio De Caso De La Cuenca Hidrográfica De La Corriente De Arapuá - Três Lagoas/MS

Ruth Helena Marquezani Rocha Mestranda de Geografia, UFMS, Brasil ruthhmrocha@gmail.com

Nathália Pereira Dourado Mestranda de Geografia, UFMS, Brasil. nathaliaadourado@gmail.com

Patricia Helena Mirandola Garcia Professora Doutora, UFMS, Brasil patriciaufmsgeografia@gmail.com 
RESUMO

O presente trabalho tem como objetivo a análise do Córrego do Arapuá, por meio do uso de Geotecnologias e do Geoprocessamento dos dados, com a utilização do software Spring e Arc Gis. A pesquisa tem como área de estudo o Córrego do Arapuá na proximidade com o distrito de Arapuá, no município de Três Lagoas-MS. Na metodologia aplicada, foram realizadas as etapas do geoprocessamento de dados referentes à região do Córrego, que ocorreram a partir dos dados do satélite Alos Polsar, da Universidade do Alasca, no software Global Mappers, para delimitação da área e correção a partir das curvas de nível na área, seguida da obtenção de imagens do satélite Sentinel 2 com as bandas 8R (infravermelho) 4G (vermelho) e 3B (verde), em configuração RGB, possibilitando realizar composição colorida para a retirada de atributos da região de análise, resultado utilizado para a segmentação e classificação do uso e cobertura, identificando, desse modo, os tipos de informações e itens das categorias de análise segundo o IBGE - Instituto Brasileiro de Geografia e Estatística. Concluímos o trabalho discutindo as possíveis ações que geraram o predomínio da Área de Pastagem, seguido pela Silvicultura, Vegetação nativa e por último á análise da Área urbana. A pesquisa foi realizado com apoio da Universidade Federal de Mato Grosso do Sul - UFMS/MEC - Brasil e pela bolsa de pesquisa de Coordenação de Aperfeiçoamento de Pessoal de Nível Superior - CAPES/MEC - Brasil.

PALAVRAS-CHAVE: Análise Ambiental, Bacia Hidrográfica, Córrego, Geografia, Geoprocessamento.

\begin{abstract}
The present work aims to analyze the Arapuá Stream, through the use of Geotechnologies and Data Geoprocessing, using the Spring and Arc Gis software. The research has as its study area the Córrego do Arapuá in proximity to the district of Arapuá, in the municipality of Três Lagoas-MS. In the applied methodology, the steps of geoprocessing of data related to the Córrego region were carried out, which occurred from the data of the Alos Polsar satellite, from the University of Alaska, in the Global Mappers software, for delimiting the area and correction from the curves of level in the area, followed by the acquisition of images from the Sentinel 2 satellite with the bands $8 R$ (infrared) $4 G$ (red) and $3 B$ (green), in RGB configuration, making it possible to perform colored composition for the removal of attributes from the analysis region, result used for segmentation and classification of use and coverage, thus identifying the types of information and items in the analysis categories according to IBGE - Brazilian Institute of Geography and Statistics. We concluded the work by discussing the possible actions that generated the predominance of the Pasture Area, followed by Silviculture, Native vegetation and finally the analysis of the urban Area. The research was carried out with support from the Federal University of Mato Grosso do SUl - UFMS / MEC - Brazil and by the research grant from the Coordination for the Improvement of Higher Education Personnel - CAPES / MEC - Brazil.
\end{abstract}

KEY WORDS: Environmental analysis, hydrographic basin, Stream, Geography, Geoprocessing.

\title{
RESUMEN
}

El presente trabajo tiene como objetivo analizar la corriente de Arapuá, mediante el uso de geotecnologías y geoprocesamiento de datos, utilizando el software Spring y Arc Gis. La investigación tiene como área de estudio el Córrego do Arapuá cerca del distrito de Arapuá, en el municipio de Três Lagoas-MS. En la metodología aplicada, se llevaron a cabo los pasos del geoprocesamiento de los datos relacionados con la región de Córrego, que se produjo a partir de los datos del satélite Alos Polsar, de la Universidad de Alaska, en el software Global Mappers, para delimitar el área y la corrección de las curvas de nivel en el área, seguidas por la adquisición de imágenes del satélite Sentinel 2 con las bandas $8 R$ (infrarrojo) $4 G$ (rojo) y $3 B$ (verde), en configuración $R G B$, lo que permite realizar una composición en color para la eliminación de atributos de la región de análisis, resultado utilizado para la segmentación y clasificación de uso y cobertura, identificando así los tipos de información y elementos en las categorías de análisis de acuerdo con IBGE - Instituto Brasileño de Geografía y Estadística. Concluimos el trabajo discutiendo las posibles acciones que generaron el predominio del área de pastoreo, seguido de la silvicultura, la vegetación nativa y finalmente el análisis del área urbana. La investigación se llevó a cabo con el apoyo de la Universidad Federal de Mato Grosso do SUI - UFMS / MEC - Brasil y por la beca de investigación de la Coordinación para el Mejoramiento del Personal de Educación Superior - CAPES / MEC - Brasil.

PALABRAS CLAVE: Análisis ambiental, Cuenca hidrográfica, Córrego, Geografía, Geoprocesamiento. 


\section{INTRODUÇÃO}

Fundamental para a vida do planeta, os recursos hídricos são essenciais para o equilíbrio da sociedade e da natureza; sendo assim, foram criados ao longo dos anos, planejamentos adaptados nas bacias hidrográficas, a fim de que haja a disponibilidade hídrica no consumo e a preservação da sustentabilidade dos seus recursos em manter a qualidade e quantidade das águas.

Com a denominação como uma unidade territorial, a bacia hidrográfica é estabelecida para implementação da Política Nacional de Recursos Hídricos e atuação do Sistema Nacional de Gerenciamento de Recursos Hídricos (BRASIL, 1997).

A bacia hidrográfica é constituída como unidade natural de análise ambiental para exemplo de atuação de planejamento, sendo ela um território onde se exercem ocupações de diversas atividades do homem dentro de um processo de (re)produção do seu espaço.

Quanto as transformações ocorridas no espaço geográfico, nos últimos anos, vêm se ampliando em debates e discussões em diversas ciências, e a geografia tem se firmado nos estudos referentes ao seu objeto de estudo, que é a sociedade e a natureza, por meio do qual se discutem os altos índices de degradação dos recursos naturais, conforme Cardoso e Aquino (2013).

O modo de produção capitalista avança e, com ele, ocorre o uso acentuado e desordenado das terras, alastrando-se também sobre as Áreas de Preservação Permanente (APPs), principalmente as que protegem os recursos hídricos.

As Geotecnologias são um instrumento necessário para tomar decisões, englobadas em diversas áreas, sendo importantes em gestão ambiental e na educação. Assim, direcionam-se não apenas a áreas profissionais e técnicas, como também uma ferramenta favorável à ciência geográfica, para o professor, em sua prática de ensino.

Nos dias atuais, as tecnologias direcionadas para a análise do espaço geográfico têm apontado resoluções seguras para fomentar o processo de gestão e as determinações futuras na organização do espaço. Na perspectiva geográfica, o Geoprocessamento, os Sistemas de Informação Geográfica, o Sensoriamento Remoto e outras tecnologias são ferramentas importantes para a leitura e interpretação dos fenômenos no espaço geográfico, denominados como instrumentos essenciais para fins de ordenamento territorial, análise e monitoramento ambiental (AQUINO; VALLADARES, 2013).

A realização do trabalho é resultado da disciplina de Geotecnologias aplicadas ao planejamento e gestão de águas, do curso de pós-graduação em Geografia da Universidade Federal de Mato Grosso do Sul, a partir do qual foram inicialmente realizadas aulas para compreensão do processo da utilização de Geotecnologias na obtenção e geoprocessamento de dados de uma área de estudo.

Contudo, a disciplina ocorreu ao longo de uma semana, de modo a proporcionar, nas duas primeiras aulas, a elaboração de um mapa do Córrego da Onça no município de Três Lagoas-MS, como exemplo para compreender os procedimentos necessários para o estudo de um córrego. Após a elaboração desse mapa, foram realizadas três aulas com discussão acerca de políticas, órgãos e métodos de análise de bacias hidrográficas, como o manejo e gestão das mesmas. A bacia hidrográfica escolhida para realizar o estudo com as geotecnologias para a pesquisa, foi a Bacia do Córrego do Arapuá, localizada no distrito de Arapuá, pertencente à cidade de Três Lagoas, no estado do Mato Grosso do Sul (MS). 


\section{OBJETIVOS}

Busca-se com a realização do trabalho identificar os tipos de coberturas presentes no Córrego do Arapuá, distrito do município de Três Lagoas-MS e discutir os resultados encontrados, com a análise das possíveis causas e impactos das ações humanas observadas na configuração dos seus limites.

\section{METODOLOGIA/MÉTODO DE ANÁLISE}

Para o estudo das geotecnologias aplicadas na bacia hidrográfica do Córrego do Arapuá, a metodologia desta pesquisa está baseada em 04 etapas, que estão interligadas:

A pesquisa é referente da disciplina de Geotecnologias aplicadas ao planejamento e gestão de águas, do Programa de pós-graduação em Geografia, cursos de mestrado e doutorado acadêmico pela Universidade Federal de Mato Grosso do Sul, Campus de Três Lagoas, realizada com aulas teórias acerca das geotecnologias e elaboração de mapas, como também as metodologias de análise de recursos hídricos, planejamento e gestão de bacias, considerando que a teoria e a prática caminham juntas.

A escolha da área ocorreu mediante a sua proximidade com o distrito de Arapuá, localizado no município de Três Lagoas-MS, de modo a contribuir para os estudos a serem realizados no distrito e em suas proximidades, além do fato de ser cortado pela Rodovia 262, que dá acesso ao mesmo e que altera a formação inicial do córrego, podendo tanto causar transtornos para o córrego, dificultando a chegada da água até outras partes, quanto possíveis inundações da rodovia em períodos de cheia.

A coleta de dados foi possível, por meio da utilização de dados de dois satélites: Alos Polsar e Sentinel 2, cujas imagens encontram-se em boa resolução para análise de seus dados nos softwares Arcgis e Spring, por meio do Geoprocessamento das imagens, conforme o mapa na Figura 1. 
Figura 1: Mapa de localização do Córrego Arapuá

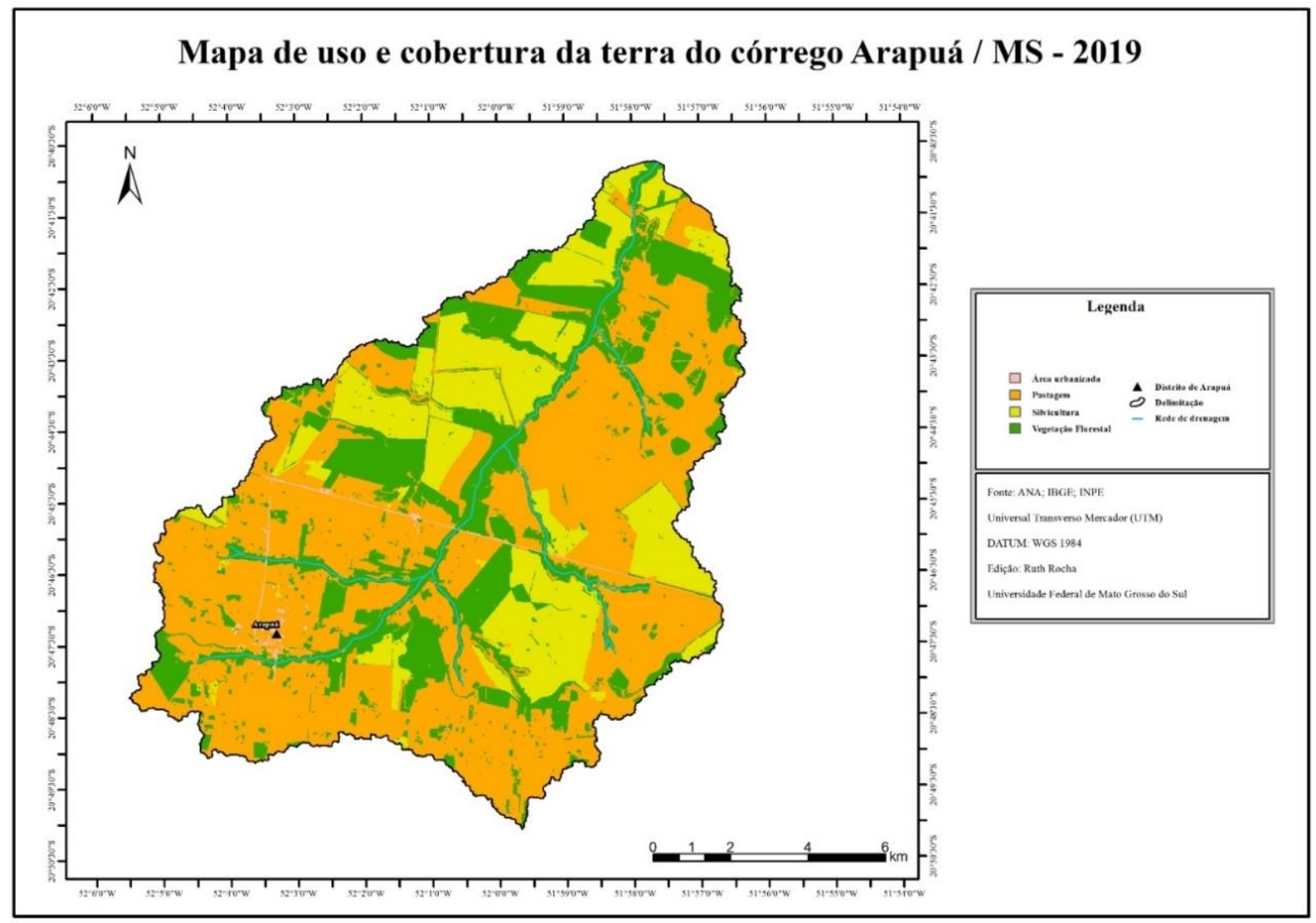

Fonte: ANA, IBGE, INPE, editado por ROCHA, 2019.

Inicialmente, foram utilizadas imagens do satélite Alos Polsar, da Universidade do Alasca, de modo a delimitar o perfil do Córrego Arapuá, tendo seu recorte a partir da obtenção dos limites do córrego, processo realizado em sequência, com o uso de dois softwares, o Global Maps e o Arcgis.

Para a obtenção dos pontos e órbitas dos limites do córrego, utilizou-se o software Global Maps, no qual foi possível identificar as coordenadas do limite estabelecido para a área de estudo; para melhor delimitação, os dados foram exportados para o software Arcgis de modo a fazer ajustes nos pontos do limite a partir das curvas de nível, com os pontos: Path 69 e Frame 6770, e Path 69 e Frame 6760.

Após a realização do recorte das imagens de satélite, nos limites do córrego, os dados foram transformados para serem importados para o Spring; com os dados transferidos para o novo software, foram baixadas imagens do satélite Sentinel 2 das bandas 8,4 e 3, com a seleção de 
RGB, para realizar o recorte e a composição colorida, cujo recorte de suas bandas possibilitou realizar a composição colorida.

As imagens baixadas do Satélite Alos Polsar, da Universidade do Alasca, referentes ao dia $27 / 12 / 2010$, e bandas de imagens, pelo satélite Sentinel 2, referentes ao dia 10/07/2019, correspondem ao período seco, sem cobertura de nuvens, período propício para a coleta de informações devido a sua nitidez na obtenção das informações trabalhadas no Spring, com o formato em FBD. Portanto, tem-se que:

\begin{abstract}
As fotografias aéreas, as imagens de radar e as imagens de satélite revelam através do espectro visual basicamente a rugosidade topográfica dada pelo relevo (textura grosseira) e a textura fina, dada pela vegetação, que dá em diferentes cores, padrões diferenciados em função do tipo de cobertura vegetal. A combinação dessas duas variáveis (relevo-vegetação), fornece diferentes distinções de padrões fisionômicos. (ROSS, 1995, p.71).
\end{abstract}

Padrões esses que podem ser observados durante o processamento da composição colorida, sendo possível destacar caraterísticas de sua área, como as áreas urbanizadas, áreas de Pastagem, de Silvicultura, área com vegetação, visto que cada banda possui uma resolução diferente da outra, permitindo possíveis combinações com as diferentes bandas disponibilizadas pelo satélite.

O satélite Sentinel 2 fornece 13 bandas de imagens, porém, devido ao objetivo de realizar a composição colorida e o mapeamento do uso e cobertura do córrego, foram utilizadas a bandas 8R (infravermelho), 4B (vermelho) e 3G (verde), com informações de proximidade $10 \mathrm{~m}$ da área, tendo, entre seus objetivos, a geração de dados para elaboração de mapas de uso e cobertura. Após realizar o recorte das bandas, passou-se à segmentação das imagens, a fim de criar uma composição colorida.

Com a composição feita, o próximo passo foi a segmentação das imagens com similaridade $8 \mathrm{e}$ pixel 10, da área já recortada, resultando na criação de linhas e pontos identificados pelos pixels presentes na imagem, com o método crescimento de regiões.

Após a segmentação, realizou-se o procedimento de retirada de atributos das regiões, o que possibilitou realizar a opção treinamento de modo criar categorias para as classificações.

A Classificação ocorreu com o auxílio do Google Maps, com imagem segmentada, pixel a pixel, com limiar de aceitação de 99,9\%, para as áreas no uso e na cobertura, processo este que resultou na identificação das seguintes categorias e cores: Área urbana (rosa), Pastagem (mostarda), Silvicultura (amarelo) e Vegetação (verde), dados produzidos conforme a tabela de atributos do IBGE.

Com a classificação feita, foi gerado o mapa de uso e ocupação do córrego, assim, a última etapa concebeu a realização do layout do Mapa, com o propósito de identificar as áreas do mapa a serem discutidas no trabalho.

A elaboração de mapas de uso e cobertura permite discutir questões de manejo, degradação ambiental e possíveis causas de ações antrópicas ao meio ambiente, devido à extração e utilização dos recursos naturais, porém, não é o objetivo deste trabalho realizar uma análise multitemporal, mas, a partir da elaboração do mapa de uso e cobertura, discutir a degradação ambiental e, principalmente, a falta de água no córrego, pois os recursos naturais são utilizados 
pelo ser humano, desde plantações em grande escala, como se verá no predomínio dos eucaliptos e de área de pastagem.

Assim, pode-se afirmar que a utilização dos softwares permitiu fazer a análise dos modos de uso e cobertura no córrego como também, a partir dos resultados presentes no mapa, discutir questões ambientais, diante da crescente utilização de recursos naturais pelo homem.

A revisão de literatura ocorreu como última etapa a medida que os estudos a respeito das questões hídricas de forma geral já tinham sido feitas em sala de aula na disciplina, cujo o objetivo era entender os processos que envolvem a utilização dos recursos hídricos, por meio do manuseio e elaboração de mapas, com dados da áreas, com o uso de softwares nas discussões acerca do estudo. Além, de já terem visitados áreas da delimitação do córrego, como o distrito de Arapuá localizado em seus limites.

\section{RESULTADOS}

A área de estudo do Córrego Arapuá, por meio do mapeamento de uso e cobertura de sua área, com a utilização de geotecnologias no processo de coleta de dados e geoprocessamento, permitiu analisar questões ambientais, a respeito da utilização dos recursos naturais pelo homem, com o propósito de discutir degradações ambientais, alterações, e atual configuração do córrego, a partir de autores como ROSS (2011), que terá destaque para a análise e discussão da área do córrego.

Com o geoprocessamento dos dados, a partir de imagens do satélite do Sentinel 2 e do Alos Polsar, foram geradas informações de uso e cobertura do córrego, com a identificação das seguintes categorias, em ordem de área ocupada, da maior para a menor: Pastagem, Silvicultura, Vegetação, área urbanizada.

Dessa forma sendo possível identificar alterações em sua formação natural, considerando que o córrego se encontra em uma região de cerrado, cuja formação arbórea não é constituída por Eucalipto nem soja, ou seja, árvores de grande porte, mas, sim, de pequeno porte e com raízes profundas.

Conforme Ross (2011), as leis da física e da química promovem os diversos estados da natureza e esta, por não sofrer alterações humanas em sua essência, tem a capacidade de se autorregenerar. Desse modo, entende-se, segundo o autor, que a natureza possui capacidade de se regenerar, desde que seu uso ocorra de forma a permitir sua própria realização, ausente de intervenções humanas até completar sua regeneração. Não se descrimina aqui o uso dos recursos naturais, mas discutem-se a maneira como a utilização exacerbada desses recursos ambientais pode causar danos à natureza e as medidas e ações que respeitem os seus limites. Para Ross (2011), o estudo do uso da terra representa o retrato estático de manifestações que acontecem de forma dinâmica, no que se refere aos interesses socioeconômicos de utilização desses recursos, ou seja, o "cenário atual" dos fluxos das relações estabelecidas entre sociedade-natureza.

Portanto, analisar uma área a partir dos modos de uso e cobertura leva à discussão de como as relações entre sociedade e natureza são estabelecidas. No córrego, percebe-se o predomínio de áreas de pastagem e plantações de silvicultura; assim, as áreas com vegetação natural, sem a 
intervenção humana, de modo a colocar outro elemento em seu lugar ou sem cortá-las, encontram-se apenas maior que a área urbana.

As áreas de pastagem são outro ponto negativo para a preservação ambiental, devido a sua proximidade com o córrego, sendo que o pisoteio frequente do gado pode causar danos à cobertura vegetal, deixando o solo exposto, além das alterações nas margens dos rios.

O reduzido grupo de vegetações nativas, no meio das plantações de Silvicultura, não é um ponto positivo para as relações entre os elementos da natureza, já que acabam com a relação entre determinados elementos do ecossistema da área de estudo, além das dificuldades no acesso a alimento por parte de animais que passam ou passariam por essas áreas.

Quanto à qualidade da água a ser analisada com os resultados gerados no mapa, observam-se riscos, devido às grandes áreas plantadas de silvicultura, mediante o uso de agrotóxicos, fertilizantes, entre outros, que frequentemente são utilizados em grandes áreas de plantações, que se encontram em sua maioria junto ao canal principal do rio. Ou seja, o frequente derramamento desses produtos sobre a área do córrego pode gerar sérios problemas à qualidade da água, porém, para se analisar a qualidade em número e estatísticas, será necessário coletar amostras para a análise de $\mathrm{PH}$, o nível de produtos químicos, entre outros.

Outro elemento está ligado às extensas áreas de pastagem, que promovem mais suscetibilidade a erosões mediante a falta ou pouca cobertura vegetal, fator que deixa o solo mais vulnerável a ser degradado.

\section{CONCLUSÃO}

Com as informações obtidas acerca do Córrego Arapuá, no município de Três Lagoas-MS, encontra-se uma área alterada pelo uso da pecuária extensiva, diante da retirada de árvores para a realização da pecuária, além das grandes áreas de plantação de Silvicultura, considerando que nas áreas de pastagem existiam apenas algumas representações arbóreas, o córrego é cortado pela Rodovia 262, alteração antrópica que dificulta a chegada de água a outras partes do seu curso natural, com a possibilidade de causar inundações na rodovia durante o período de cheia.

Com a utilização das geotecnologias no geoprocessamento das imagens, foi possível realizar análise no uso e cobertura na área no Córrego Arapuá, identificando categorias que proporcionaram discutir as formas de apropriação dos recursos naturais pelo homem, como demostra a representação no mapa, devido aos poucos resquícios de vegetação original em relação à área total, com grandes porções compostas por silvicultura, sendo que essas plantações demandam anos de crescimento para a posterior colheita. Além disso, futuramente, se não existir tempo para o solo se renovar e para a rotação de cultura, a degradação ambiental nessa área pode ser alta.

Porém, para uma análise da qualidade ambiental do córrego, é necessário que aconteçam saídas de campo em períodos diferentes do ano, de modo a analisar a qualidade da água e elementos como inundações de áreas, em época de cheia. 
Por tanto, com a realização deste, procurou-se discutir a atual formação da área do córrego, buscando utilizar outros elementos e gerando uma análise mais completa e integrada em trabalhos próximos.

\section{REFERÊNCIAS BIBLIOGRÁFICAS}

AQUINO, C. M. S.; VALLADARES, G. S. Geografia, geotecnologias e planejamento ambiental. Revista Geografia, Londrina, v. 22, n.1, p. 117-138, jan./abr. 2013.

AGENCIA NACIONAL DE ÁGUAS (ANA). Disponível em: http://www.ana.gov.br acesso em agosto de 2019

BORGES, K. A. de V. Modelagem de Dados Geográficos CURSO DE ESPECIALIZAÇÃo EM GEOPROCESSAMENTO, 2002.

CÂMARA, Gilberto; MONTEIRO, Clodoveu Davis Antônio Miguel Vieira Monteiro. INTRODUÇÃo À CIÊNCIA DA GEOINFORMAÇÃO. INPE São José dos Campos 2001

CARDOSO, J. A.; AQUINO, C. M. S. Análise dos usos e cobertura das terras das microbacias hidrográficas do riacho do Roncador - Timon (MA): subsídios ao planejamento ambiental. Boletim Campineiro de Geografia, v. 3, n. 2, p. $305-327,2013$.

GOMeS; AlBuquerque, A. R. C. Planejamento Ambiental em bacias hidrográficas: um estudo preliminar de indicadores socioambientais na microbacia do Igarapé do Quarenta (Manaus-AM). In: Simpósio brasileiro de Geografia Física Aplicada, 2009, Viçosa - Mg. XIII Simpósio Brasileiro de Geografia. Viçosa - MG: Universidade Federal de Viçosa, 2009. v. XIII.

MAGALHÃES JR., A. P. Indicadores Ambientais e Recursos Hídricos: realidade e perspectivas para o Brasil a partir da experiência francesa. Rio de Janeiro: Bertrand Brasil, 2007.

MIRANDOLA, P, S; SILVA-ALMEIDA, Renan; PIRES, E.V.R.; IZIPPATO, F.J. GEOPROCESSAMENTO APLICADO A análise do uso e ocupação da terra e apps de nascentes no rio indáia grande? chapadão do sul/cassilândia/inocência (ms).. Revista GeoNorte, v. 2, p. 1497-1508, 2012.

PINHEIRO, Juliana Heloisa Pinê Améico; BENINI, Sandra Medina. (orgs). Bacias hidrográficas: fundamentos e aplicações. 2 ed. Ver. - Tupã: ANAP, 2019.

PORTO, M. F. A.; PORTO R. L. L. Gestão de Bacias Hidrográficas. Revista de Estudos Avançados. Vol.22, no.63. São Paulo, 2008.

QUEIROZ, F. L. L. ASPECTOS DA DINÂMICA HIDROSSEDIMENTOLÓGICA E DO USO E OCUPAÇÃO DO SOLO NA BACIA DO CÓRREGO ARAPUÁ (MS), 2011.

ROSA, R. Análise espacial em geografia. Revista da ANPEGE, Dourados-MS, v. 7, n. 1, número especial, p. 275-289, out. 2011.

ROSS, J. (2011). ANÁlISE E SÍNTESE NA ABORDAGEM GEOGRÁFICA DA PESQUISA PARA O PLANEJAMENTO AMBIENTAL. Revista Do Departamento De Geografia, 9, 65-75.

SILVEIRA, A. L. L. Ciclo hidrológico e bacia hidrográfica. In: Hidrologia: ciência e aplicação. Porto Alegre: Editora da Universidade do Rio Grande do Sul e Editora da Universidade de São Paulo, 1993. P. 35-51. 
TEODORO, V. L. I.; FULLER, B.B. ; TEIXEIRA, D ; COSTA, D. J. L. . O Conceito de Bacia Hidrográfica e a Importância da Caracterização Morfométrica para o Entendimento da Dinâmica Ambiental Local. Revista Brasileira Multidisciplinar - ReBram (Uniara), v. 11, p. 137, 2015.

VOLPI, E, M. Padrões para aquisição de softwares SIG por administrações públicas municipais / Edmilson Martinho Volpi. - São Carlos: UFSCar, 2006. 